\title{
Effects of lentivirus-mediated endostatin on endothelial progenitor cells
}

\author{
Jing $\mathrm{Ai}^{1, *}$, Jun-Hui Sun ${ }^{2, *}$, Jian $\mathrm{Ma}^{1}$ and $\mathrm{Ke} \mathrm{Yao}^{1}$ \\ ${ }^{1}$ Eye Center, 2nd Affiliated Hospital of School of Medicine, Zhejiang University, Hangzhou 310009, China \\ ${ }^{2}$ Key Laboratory of Combined Multi-Organ Transplantation, Ministry of Public Health, The First Affiliated Hospital, School of \\ Medicine, Zhejiang University, Hangzhou 310003, China \\ *These authors have contributed equally to this work \\ Correspondence to: Ke Yao, email: xIren@zju.edu.cn \\ Keywords: endostatin; endothelial progenitor cells; lentiviral vector; gene transfer; cell viability \\ Received: July 18, $2017 \quad$ Accepted: September 20,2017 Published: October 10, 2017 \\ Copyright: Ai et al. This is an open-access article distributed under the terms of the Creative Commons Attribution License 3.0 \\ (CC BY 3.0), which permits unrestricted use, distribution, and reproduction in any medium, provided the original author and source \\ are credited.
}

\section{ABSTRACT}

Endothelial progenitor cells (EPCs) are candidates for gene therapies against retinal neovascularization (NV). The aim of present study was to investigate the effects of endostatin transfection on EPC function. In the present study, the EPCs were infected with lentivirus overexpressing endostatin. The transfection effects of endostatin overexpression on the proliferation, migratory, differentiation, apoptosis and the cell cycle of this cell line were determined. The real-time quantitative polymerase chain reaction (RT-qPCR) and western blot assays showed high expression levels of endostatin. A cell counting kit-8 assay showed that endostatin overexpression inhibited EPC proliferation. The transwell assay indicated that endostatin overexpression could suppress EPC migration. Furthermore, endostatin overexpression enhanced apoptosis (as showed by AnnexinV-FITC/propidiumiodide staining analysis), induced differentiation and blocked the cell cycle. As compared with negative control group, EPC viability significantly decreased in gene transfection group. In conclusion, present study determined the feasibility of lentivirus-mediated endostatin gene transfer, and indirectly proved the effect of endostatin secretion on EPCs. Also our study provided a new opportunity for the potential application of gene therapy in retinal NV.

\section{INTRODUCTION}

Endostatin is a $20 \mathrm{kDa}$ C-terminal fragment of collagen XVIII with antiangiogenic activity. It specifically inhibits endothelial cell (EC) proliferation and potently inhibits angiogenesis and tumor growth [1-2]. It was reported that endostatin could offer an innovative pharmaceutical strategy for the prevention of retinal neovascularization (NV) [3]. However, a good therapeutic effect requires long-term administration, which is expensive and time-consuming. Endostatin is not stable and its transient effect limits its widespread clinical application. Lentiviral vectors are particularly advantageous and receive much attention due to their stable delivery of the transferred gene into the host cell's chromosomes [4-6]. Thus, gene transfer strategies [712] have the potential to provide sustained, high, local concentrations of antiangiogenic mediators to prevent progression of ocular NV [13-15].

Endothelial progenitor cells (EPCs) have been identified as circulating cells with considerable diagnostic and therapeutic value [16-21]. For example, EPCs can be injected intravitreally into mice with oxygen-induced retinopathy (OIR) to repair the injured retina [16]. Transfected EPCs migrate to the sites of vascular injury to revascularize ischemic tissues [17]. The therapeutic effects of EPCs have been demonstrated in patients with ischemic or $\mathrm{NV}$ disease and in autologous EPC populations, representing 
a novel approach to therapeutic revascularization [18-20]. The genetic engineering of progenitor cells with angiogenic growth factors may be a strategy to enhance the activity of injected progenitors. We hypothesized that EPCs transfected with endostatin could serve as a vehicle for continuous delivery of endostatin to retinal NV tissues.

The present experiment was designed to investigate the potential utility of lentiviral vectors for achieving efficient and stable endostatin expression via gene transfer. The viability of EPCs transfected with the lentivirusmediated endostatin gene was also investigated.

\section{RESULTS}

\section{Increased endostatin expression in transfected EPC line}

Puromycin-resistant individual clones of transgenic endostatin overexpressing EPCs were manually chosen. Total RNA was isolated from the cells in each group. Compared to the NC (negative control EPCs which were transduced with empty vector expressing GFP) group, the endostatin mRNA levels in the endostatin overexpression (OE) group (EPCs which were transduced with recombinant lentiviral vectors expressing both GFP and endostatin) were significantly increased $(P<0.001)$; but the endostatin mRNA levels in the blank control (non-transduced EPCs) and NC groups did not increase significantly (Figure 1A).

Western blot analysis (Figure 1B and 1C) demonstrated that endostatin was expressed in the blank control, $\mathrm{NC}$, and endostatin $\mathrm{OE}$ groups. Compared to the NC group, the endostatin protein expression levels were significantly increased in the endostatin OE group $(P<0.001)$. The endostatin protein expression levels were also significantly increased in the blank control group $(P<0.01)$.

\section{Cell viability}

\section{Decreased cell proliferation}

Compared to the NC group, the cell proliferation rate was significantly decreased in the endostatin $\mathrm{OE}$ group $(P<0.001)$. In contrast, there was no difference in the cell proliferation rates between the blank control group and the NC group (Figure 2).

\section{Decreased cell migration}

Representative images showed that migrating cells stained with crystal violet in the endostatin OE group were significantly decreased as compared to the blank control and the NC groups (Figure $3 \mathrm{~A})(P<0.01)$. In contrast, there was no significant difference of EPC migration activity levels between the blank control and NC groups (Figure 3B).

\section{Restrained cell growth}

Fluorescence-activated cell sorting (FACS) analysis of the cell cycle showed an increased proportion of cells in the $\mathrm{G}_{1}$ phase and a decreased proportion of the Sand $\mathrm{G}_{2}$ phases in the endostatin OE group compared to the NC group $(P<0.001)$ (Figure 4$)$. This indicated that the majority of endostatin-overexpressing EPCs stayed at the $\mathrm{G}_{1}$ stage, proving that cell growth was affected and restrained (Table 1, Figure 4). However, there was no difference between the blank control and $\mathrm{NC}$ groups $(P>0.05)$.

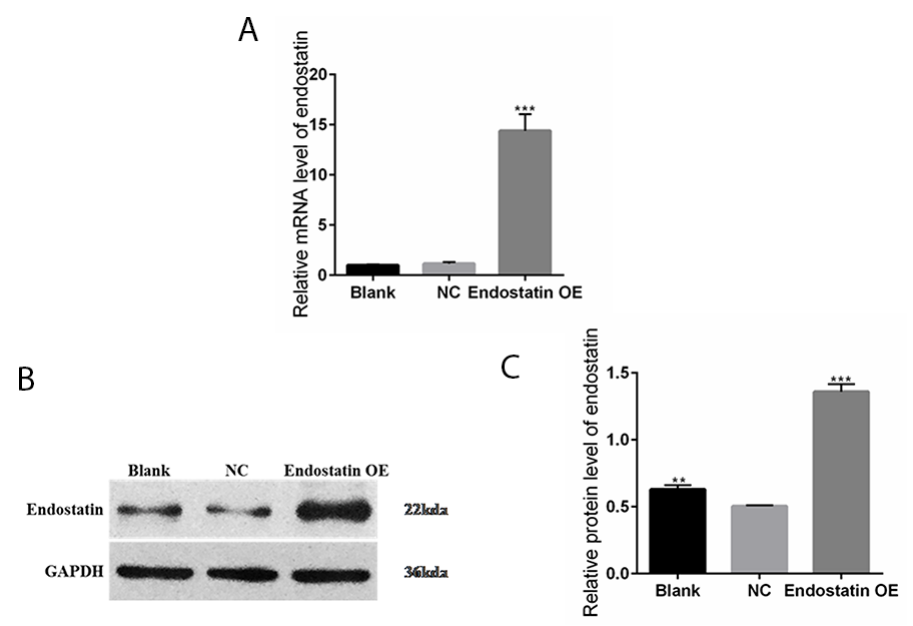

Figure 1: Increased endostatin expression in transfected EPC line. Blank: blank control group, NC: negative control group, endostatin OE: endostatin overexpression group. (A) Relative mRNA expression levels of endostatin in EPCs detected with qRT-PCR. Compared with $\mathrm{NC},{ }^{* * *} P<0.001$. (B) Endostatin protein expression levels measured by band intensity analysis. The GAPDH protein served as an internal control. (C) The relative protein expression levels of endostatin in EPCs detected by Western blot assays. Compared with $\mathrm{NC},{ }^{* *} P<0.01,{ }^{* * *} P<0.001$. 


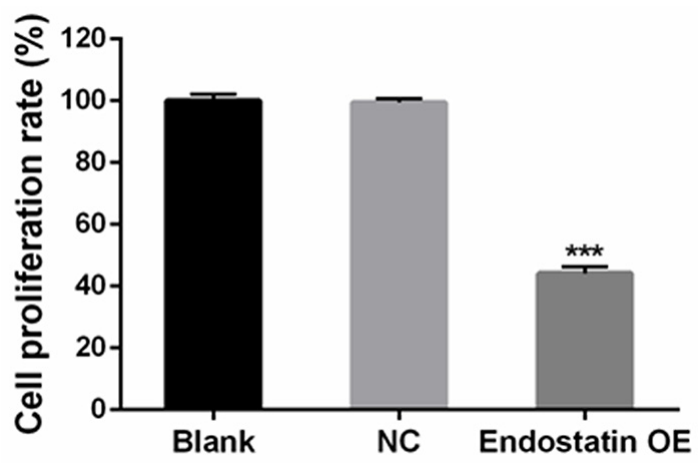

Figure 2: Decreased cell proliferation. Cells were seeded in 96-well plates. Effects on cell proliferation ability were analyzed with CCK-8 assays. Blank: blank control group, NC: negative control group, endostatin OE: endostatin overexpression group. Compared with $\mathrm{NC},{ }^{* * *} P<0.001$.

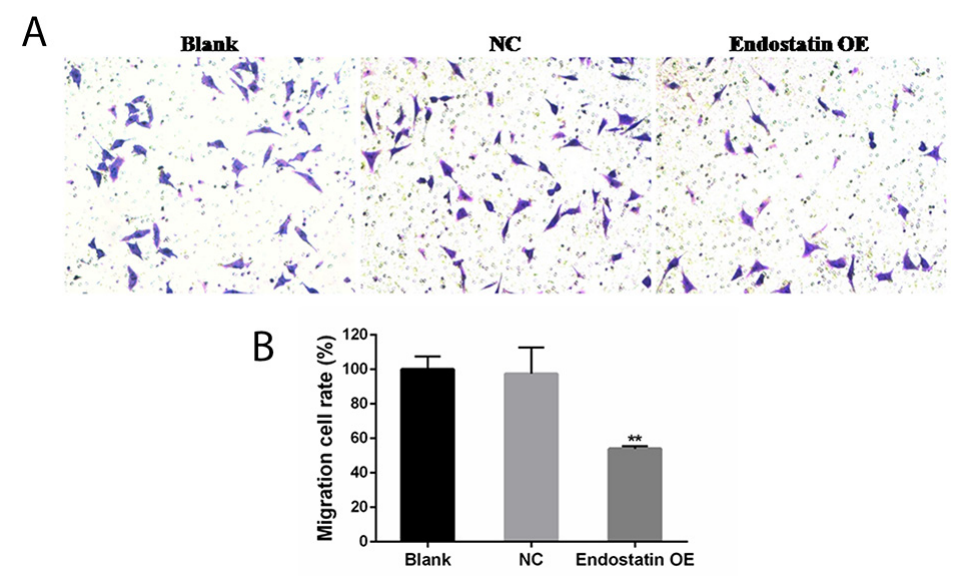

Figure 3: EPC migration inhibited by endostatin overexpression. Blank: blank control group, NC: negative control group, endostatin OE: endostatin overexpression group. Compared with $\mathrm{NC},{ }^{* *} P<0.01$. (A) EPCs $(50,000$ per transwell chamber) were seeded in DMEM without FBS in the upper compartment of transwell chambers; lower chambers were filled with DMEM containing $10 \%$ FBS. The bottom sides of the filters were stained with crystal violet to count the cells that migrated across the filter. Representative images are shown. Migrating cells were viewed under a microscope $(200 \times)$. (B) Effects of endostatin gene transfer on EPC migration. The graph represents migration cell rate $(\%)$ of different groups.
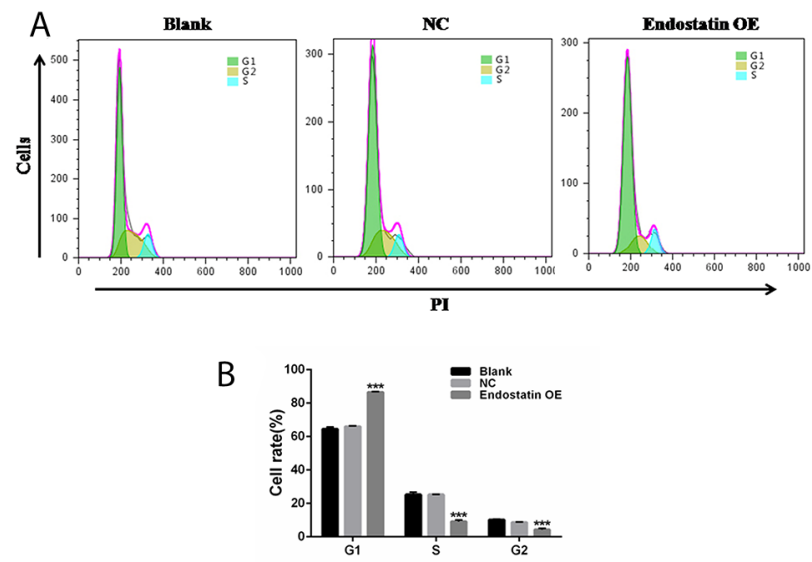

Figure 4: Cell cycle analysis. Blank: blank control group, NC: negative control group, endostatin OE: endostatin overexpression group. Compared with $\mathrm{NC},{ }^{* * *} P<0.001$. (A) Flow cytometry analysis of cell cycle. (B) Cell rates of EPCs at different cell cycles. The histogram shows the rates ofthe $\mathrm{G}_{1}, \mathrm{~S}$, and $\mathrm{G}_{2}$ phases of the cell cycle for different groups. 
Table 1: Percentages of EPCs at different cell cycle phases $(\%$, mean \pm SD)

\begin{tabular}{lccc}
\hline Group & $\mathbf{G}_{\mathbf{1}}$ phase & S phase & $\mathbf{G}_{\mathbf{2}}$ phase \\
\hline Blank & $64.51 \pm 1.16$ & $25.25 \pm 1.47$ & $10.24 \pm 0.31$ \\
NC & $66.01 \pm 0.38$ & $25.28 \pm 0.15$ & $8.71 \pm 0.24$ \\
Endostatin OE & $86.57 \pm 0.35^{* * *}$ & $9.14 \pm 0.98^{* * *}$ & $4.31 \pm 0.79^{* * *}$ \\
\hline
\end{tabular}

Note: Blank: blank control group, NC: negative control group, Endostatin OE: endostatin overexpression group. Compared with $\mathrm{NC},{ }^{* * *} P<0.001$.

\section{Increased cell apoptosis}

The results of flow cytometry using AnnexinVFITC/ PI staining indicated that the rate of apoptosis in the endostatin $\mathrm{OE}$ group was significantly increased compared to the NC group $(P<0.001)$, but there was no difference between the blank control and $\mathrm{NC}$ groups (Figure 5).

\section{Decreased cell differentiation}

The results of flow cytometry, seen in Figure 6, showed that the percentage of $\mathrm{CD} 31^{+}$cells was decreased $(P<0.001)$, while the percentage of $\mathrm{CD} 31^{-}$cells was significantly increased $(P<0.001)$ in the endostatin $\mathrm{OE}$ group compared to the $\mathrm{NC}$ group. As $\mathrm{CD} 31^{+}$is a marker of endothelial cell (EC), differentiation in the endostatin OE group was significantly decreased compared to the NC group. There was no difference between the blank control and NC groups (Figure 6).

\section{DISCUSSION}

EPCs are cells of mesodermal origin found in the bone marrow, spleen, umbilical cord blood, and peripheral blood [21]. When NV (angiogenesis or vasculogenesis) occurs, EPCs are mobilized from the bone marrow to the site of NV, and subsequently differentiate into endothelial cells [22-24]. The generation of neovascular-resistant EPCs resulted in the clinical interest, due to the EPC's therapeutic potential and the EPC's pathogenic role in NV [21-24]. Endostatin (ananti-angiogenicagent) potently inhibits angiogenesis and has demonstrated anti-tumor effects when delivered continuously [2, 25]. Moreover, lentiviruses have the potential to achieve long-term stable expression and maintain therapeutic levels of secreted peptides [4-6]; therefore, lentivirus-mediated gene delivery of antiangiogenic factors has applications in both functional genomics and clinical studies [26, 27$]$.

In the present study, recombinant lentivirus vectors transfected with endostatin on EPCs were developed to
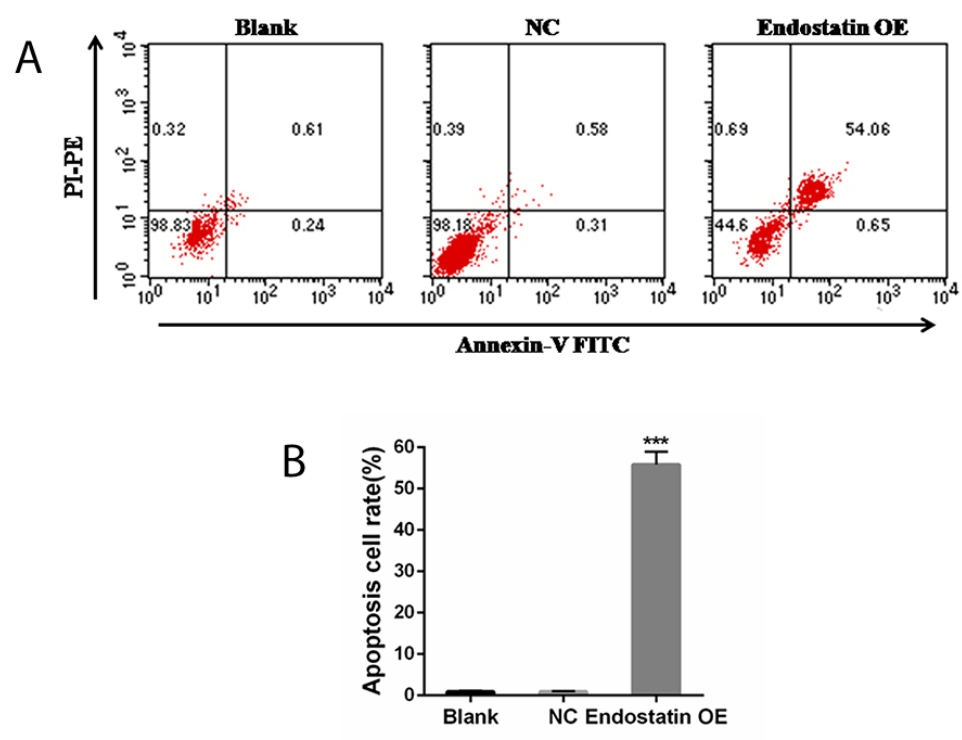

Figure 5: Cell apoptosis analysis. Blank: blank control group, NC: negative control group, endostatin OE: endostatin overexpression group. Compared with $\mathrm{NC},{ }^{* * *} P<0.001$. (A) Flow cytometry analysis of cell apoptosis. PI: propidium iodide, FITC: fluorescein isothiocyanate, PE: phycoerythrin. (B) Apoptosis cell rates of different groups (\%). 
increase long-term endostatin expression. It was observed that EPCs can be genetically modified to overexpress endostatin in a stable fashion. Providing sustained, high, local concentrations of endostatin is possible by increasing endostatin secretion via a gene transfer directly to EPCs.

We investigated the effects of lentiviral-vectormediated gene transfer of endostatin on the responses of EPCs. It was hoped that endostatin gene transfection of EPCs could enhance EPC's cell viability, because previous studies $[17,30]$ reported that gene transfection enhanced EPC's cell viabilily. For example, transfection of EPCs with the VEGF gene enhances EPC proliferation, adhesion, and incorporation into endothelial cell monolayers [30]. It was suggested that gene delivery combined with EPC transplantation may be a practical and promising therapy for the prevention of neointimal formation after vascular injury. However, the results of the present study contradicted the results of other studies. The results of present study showed that the cellular viability (proliferation, migration, and differentiation abilities) was decreased, the cell cycle was inhibited, and apoptosis was induced in EPCs with endostatin transfection, as compared with control group (EPCs without endostatin transfection). The different results between the present study and other studies may have various causes. First, the functions of transfected genes may be different, and angiogenic factors, such as vascular endothelial growth factor (VEGF), promote proliferation, migration, proteolytic activity, and capillary tube formation in endothelial cells [28, 29]. Hepatocyte growth factor (HGF) can induce endothelial cell proliferation and migration and improve endothelial function [31, 32], while endostatin, as an endogenous inhibitor of angiogenesis, directly affects endothelial cell function by inhibiting proliferation and migration, blocking endothelial cell motility, inducing apoptosis [1, 3,33 ], and potently suppressing angiogenesis and tumor growth in animal models [2]. Therefore, endostatin may have some adverse effects on EPCs. Secondly, in the present study, there was no significant difference in cell viability between the NC group (transfected with an empty vector expressing GFP) and the blank control group, suggesting that the gene transfection procedure did not affect EPC viability.

As stated above, cell viability may be affected by endostatin secretion from endostatin-transfected EPCs. However, the results of in vitro experiments cannot be applied directly to the human being, therefore, the experimental animal studies are required before the clinical trial. The mechanism of the effects on EPC viability from genes transfected with endostatin should also be investigated.

In conclusion, the present in vitro study successfully determined the feasibility of lentivirus-mediated endostatin gene transfer and indirectly proved that endostatin secretion has an effect on EPCs. We expected that the cell viability of endostatin transfected EPCs was increased, because some previous studies reported that EPC viability was enhanced by gene transfection [17, 30]. However, our result showed that the cell viability was decreased. The different results may be due to the different transfected genes [28-29, 31-33]. The transfected genes used in previous studies were VEGF and HGF, which could enhance the cell viability. But the transfected gene used in our study was anti angiogenic factor gene (endostatin), which could inhibit the cell viability. On the other hand, there was a control group (viral transfection of no load gene) in our study, which could determine that the transfection procedure did not influence the cell viability.
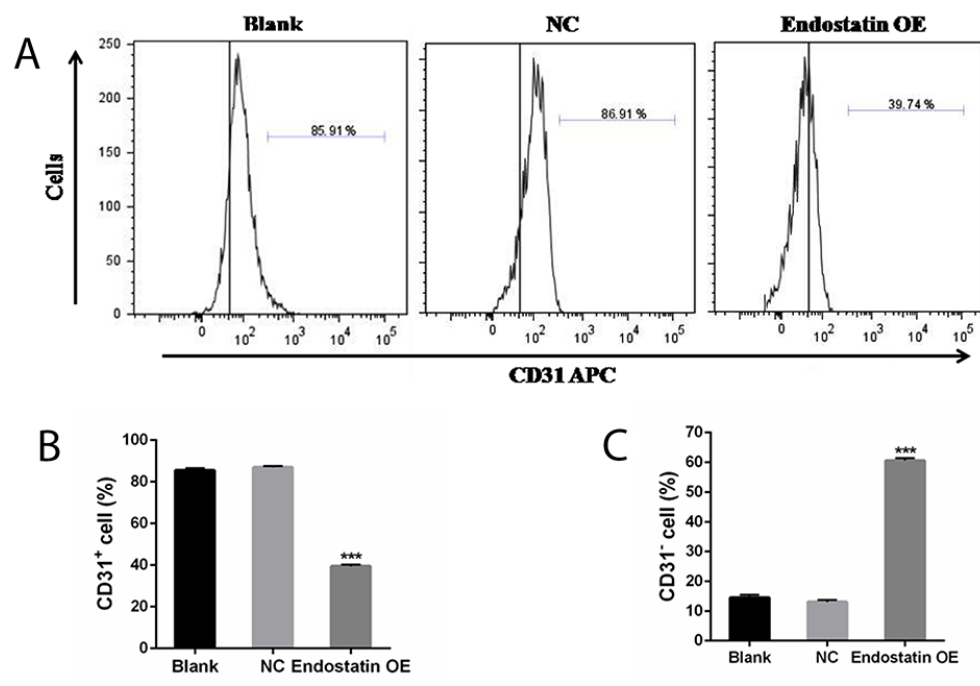

Figure 6: Cell differentiation analysis. Percentage of CD31 cells (\%). Blank: blank control group, NC: negative control group, endostatin OE: endostatin overexpression group. Compared with $\mathrm{NC},{ }^{* * *} P<0.001$. (A) Flow cytometry analysis of CD31 APC. (B) Percentage of CD31+ cells (\%). (C) Percentage of CD31- cells (\%). 


\section{MATERIALS AND METHODS}

\section{Ethics statement}

This study received approval from the Institutional Animal Care and Ethics Committee of the 2nd Affiliated Hospital, School of Medicine, Zhejiang University (Permit Number: 2015-012). All methods performed in this study were in accordance with the approved regulations and guidelines.

\section{EPC isolation and detection}

The animals were anesthetized $10 \mathrm{~min}$ before each experiment with intraperitoneal injections of sodium pentobarbital (Sigma Aldrich Corp.; St. Louis, MO, USA) at $30 \mathrm{mg} / \mathrm{kg}$. EPCs were isolated and detected according to our previous report [34]. Briefly, to obtain peripheral blood mononuclear cells (PBMCs), blood samples from $250 \mathrm{~g}$ Sprague-Dawley rats (Laboratory Animal Center of Zhejiang University) were isolated with Ficoll-PaquePlus (GE Healthcare, USA) and centrifuged by density gradient centrifugation. The PBMCs were then plated in endothelial growth medium (EGM-2-MV; Lonza, Basel, Switzerland) on fibronectin-coated culture dishes. After $96 \mathrm{~h}$, the unattached cells were removed by washing with phosphate-buffered saline (PBS). The cultured medium was replaced every two days thereafter, and each colony was observed. After seven days in culture, the early EPCs were recognized as attached cells with a spindle-shaped morphology. The adherent cells were incubated with 1,1-dioctadecyl-3,3,3',3'-tetramethylindocarbocyaninelabeled acetylated low-density lipoprotein (Dil-AcLDL; \#L3484; Thermo Fisher; Waltham, MA, USA) and then fixed in $2 \%$ paraformaldehyde for $20 \mathrm{~min}$ and counterstained with fluorescein isothiocyanate (FITC)labeled lectin from ulexeuropaeus agglutinin (UEA-1) (Abcam, Cambridge, UK). Images were acquired under fluorescent microscopy (Motic, China). Cells were also characterized by expression of CD34, CD133, CD31, and Flk-1/VEGFR2. The primary antibodies, anti-CD31 (Abcam, Cambridge, UK), anti-CD34 (Santa Cruz, Dallas, TX, USA), anti-CD133 (Proteintech, Chicago, IL, USA), and anti-CD31 (Abcam, Cambridge, UK) were utilized.

\section{Recombinant lentivirus construction and transduction of EPC line}

The endostatin fragment was amplified with polymerase chain reaction (PCR). The upstream and downstream primers, respectively, were as follows: B2085CEF 5'-AGGGTTCCAAGCTTAAGCGGCCGCG CCACCATGCATACTCATCAGGACT-3' and B2085CER 5'-ATCAGTAGAGAGTGTCGGATCCTTATTTGGAGAA AGAGGTCATGAAG- $3^{\prime}$. The clone was between the Not I and BamH I restriction sites. The transfections with the lentiviral (LV) transfer construct (LV5-EF1a-GFP+PURO) encoding green fluorescent protein (GFP) (Shanghai Gene Pharma Co., Ltd., China) were performed by lipofection for stable expression. Briefly, 293T cells were transfected with plasmid pLV/helper-SL3, pLV/helper-SL4, pLV/helper-SL5, and endostatin DNA, using Lipofectamine ${ }^{\circledR} 2000$ reagent (Invitrogen, Grand Island, NY, USA) according to the manufacturer's instructions. Recombinant lentivirus (LV5EF1a-GFP+PURO-endostatin) was collected from 48 to $72 \mathrm{~h}$ after transfection, concentrated by low-speed centrifugation at $3,000 \mathrm{~g}$ for $15 \mathrm{~min}$, and filtered through a $0.45 \mu \mathrm{m}$ filter. The viral supernatant was concentrated by ultracentrifugation at $50,000 \mathrm{~g}$ for $90 \mathrm{~min}$ and stored at $-80^{\circ} \mathrm{C}$.

For EPC transduction, the cells were re-suspended in Dulbecco's minimum essential medium (DMEM) (HyClone, USA) at a density of $1 \times 10^{6}$ cells per 6-well plate, then cultured for 24h. Recombinant lentiviral vectors (LV5EF1a-GFP+PURO-endostatin) were diluted at a multiplicity of infection (MOI) of 100 in DMEM supplemented with $10 \%$ fetal bovine serum (FBS) and in the presence of $5 \mu \mathrm{g} / \mathrm{ml}$ polybrene $(5 \mu \mathrm{g} / \mathrm{ml}$; Sigma, USA). Transduction was performed in round-bottomed 6-well plates for $24 \mathrm{~h}$. After puromycin $(1 \mu \mathrm{g} / \mathrm{ml})$ selection and four consecutive days of culturing, stable transduction of the EPC line was obtained. Cells that were non-transduced and those that were transduced with an empty vector expressing GFP were used as the blank control and negative control (NC) groups.

\section{RNA extraction and reverse transcription- quantitative PCR (RT-qPCR) assays}

Total RNA was extracted from the transfected EPCs using TRIzol reagent (Invitrogen, USA) following the manufacturer's protocol. The purity of the RNA preparation was verified by spectrophotometry readings with a Nano Drop instrument (Thermo Scientific, USA) and the integrity of the extracted RNA was evaluated by separation on agarose gel. Reverse transcription was carried out with a PrimeScript ${ }^{\circledR R T}$ reagent Kit (Perfect Real Time; Takara, Dalian, China). The primers for each gene were as follows: endostatin Fwd (5-TCTCCCAAGTCGAAGACCCT-3) and endostatin Rev (5-GAACAGCAGCGAAAAGTCCC-3); VEGF Fwd (5-GTGAGCCTTGTTCAGAGCG-3) and VEGF Rev (5-GACGGTGACGATGGTGG-3); GAPDH Fwd (5-TCTCTGCTCCTCCCTGTTCT-3) and GAPDH Rev (5-ATCCGTTCACACCGACCTTC-3). Amplification was carried out as follows: $95^{\circ} \mathrm{C}$ for $3 \mathrm{~min} ; 40$ cycles at $95^{\circ} \mathrm{C}$ for $12 \mathrm{sec}$, and $62^{\circ} \mathrm{C}$ for $40 \mathrm{sec}$. All reactions were run in triplicate and the $2^{-\Delta \Delta C t}$ equation was used to analyze the relative gene expression of endostatin and VEGF, with $\mathrm{GAPDH}$ as the endogenous reference.

\section{Western blot}

Whole cells were lysed and protein samples containing $40 \mu \mathrm{g}$ of protein were separated on $10 \%$ sodium 
dodecyl sulfate-polyacrylamide gels (SDS-PAGE), then electro-transferred onto polyvinylidene fluoride (PVDF) membranes (MilliporeCorp., Bedford, MA, USA). They were then blocked in TRIS-buffered saline containing Tween 20 (TBST; China National Pharmaceutical Group Corporation; Beijing, China) and 5\% nonfat milk for 2 $\mathrm{h}$ to block nonspecific binding, then rinsed with TBST. The blots were incubated with primary first antibodies to endostatin (1:1000; Abcam, UK), VEGF (1:1,000; Proteintech, USA), and GAPDH (1:2000; MultiSciences, Hangzhou, China) at $4^{\circ} \mathrm{C}$ overnight. After the membranes were washed several times with TBST, appropriate horseradish peroxidase (HRP)-conjugated secondary antibodies (1:20,000; MultiSciences, Hangzhou, China) were added for $2 \mathrm{~h}$ at room temperature. Finally, the membranes were washed, and the enhanced chemiluminescence (ECL) substrates were detected (GE Healthcare, USA). GAPDH was used as a loading control. Data were analyzed with Gel-Pro Analyzer software.

\section{Cell-counting kit-8 (CCK-8) cell proliferation assay}

Cell proliferation was detected with CCK-8 (SAB; College Park, MD, USA) according to the manufacturer's instructions. In brief, cells were seeded in 96-well plates at a density of $3 \times 10^{4}$ cells $/ \mathrm{mL}$, and cultured at $37^{\circ} \mathrm{C}$ and $5 \% \mathrm{CO}_{2}$ overnight. Next, $100 \mu \mathrm{l}$ of CCK -8 solution reagent was added to each well (10 $\mu \mathrm{l}$ CCK-8 and $90 \mu \mathrm{LMEM})$. The plates were incubated for an additional $1 \mathrm{~h}$ at $37^{\circ} \mathrm{C}$ and $5 \% \mathrm{CO}_{2}$. The absorbance at $450 \mathrm{~nm}$ was measured with a microplate reader (DNM-9606; Beijing Prolong Co., Ltd., Beijing, China).

\section{Transwell assay}

A transwell chamber (Corning Life Sciences, Tewksbury, MA, USA) was placed into a 24-well plate. Cells in each group were digested with trypsin and resuspended in serum-free DMEM, then $0.5 \mathrm{ml}$ of cells were added to the upper chamber $\left(1 \times 10^{5}\right.$ cells $\left./ \mathrm{mL}\right)$ while 0.75 $\mathrm{ml}$ DMEM containing 10\% FBS was added to the lower chamber. After incubation at $37^{\circ} \mathrm{C}$ for $48 \mathrm{~h}$, the cells that had not migrated were removed with a cotton swab. The migrating cells in the lower chamber were fixed with $1 \mathrm{ml}$ of $4 \%$ paraformaldehyde (Solarbio, Solarbio $®$ Life Sciences, Beijing, China) at room temperature for $30 \mathrm{~min}$ and stained with crystal violet (Solarbio, Solarbio ${ }^{\circledR}$ Life Sciences, Beijing, China) staining solution for $1 \mathrm{~h}$. Five fields were randomly selected and the number of migrating cells was counted under an Olympus optical microscope (Japan).

\section{Cell cycle analysis}

The cell cycles were analyzed with flow cytometry (BD Biosciences, Franklin Lakes, NJ, USA) using the data acquisition Modfit software. Briefly, after transfection, cells were trypsinized, collected into Eppendorf tubes, washed with PBS by centrifugation at $1,000 \mathrm{~g}$ for $5 \mathrm{~min}$, and fixed in $70 \%$ ethanol at $4^{\circ} \mathrm{C}$ overnight. Cells were then centrifugated, washed with PBS, and incubated with $10 \mathrm{uL}$ RNase A (20 ug/mL; Sigma, Aldrich Corp., St. Louis, MO, USA) for $30 \mathrm{~min}$ at $37^{\circ} \mathrm{C}$. They were washed again with PBS and stained with propidium iodide (PI; BD Biosciences, Franklin Lakes, NJ, USA) and TritonX-100 (Solarbio, Solarbio ${ }^{\circledR}$ Life Sciences, Beijing, China) at room temperaturein the dark. PI fluorescence was then analyzed with flowcytometry.

\section{Cell apoptosis analysis}

The cells were trypsinized, counted, and seeded. Later, the cells were harvested and stained with AnnexinV-fluorescein isothiocyanate (FITC)/PI according to the manufacturer's instructions. Briefly, the cells were washed twice with PBS and re-suspended in binding buffer. They were subsequently incubated with $5 \mu$ of AnnexinV-FITC (BD Biosciences, Franklin Lakes, NJ, USA) and $5 \mu$ of PI at room temperature in the dark for $15 \mathrm{~min}$, then analyzed with flow cytometry.

\section{Cell differentiation analysis}

For differentiation, the cells were trypsinized, collected, washed with 0.01M PBS, and fixed with $4 \%$ paraformaldehyde for $20 \mathrm{~min}$, then centrifugated at 1,000 $g$ for $5 \mathrm{~min}$. The cells were then washed with $0.01 \mathrm{M}$ PBS and incubated with APC-CD31 antibody (Abcam, Cambridge, UK) at $4^{\circ} \mathrm{C}$ for $30 \mathrm{~min}$. They were then analyzed with flow cytometry.

\section{Statistical analyses}

SPSS19.0 (SPSS, USA) software was used for statistical analyses. Standard deviation (SD) and average values were calculated for each variable (data are mean \pm SD). Groups were compared usingone-way analysis of variance (ANOVA). A P-value of $<0.05$ indicated a statistically significant difference. Each in vitro experiment was repeated independently at least three times.

\section{Abbreviations}

EPCs: Endothelial progenitor cells; NV: neovascularization; OIR: oxygen-induced retinopathy; VEGF: vascular endothelial growth factor; HGF: Hematopoietic growth factor; GFP: green fluorescent protein; PBMCs: peripheral blood mononuclear cells; FITC: fluorescein isothiocyanate; PI: propidiumiodide; UEA: ulexeuropaeus agglutinin.

\section{Author contributions}

K.Y. and J.A. conceived, designed and supervised the research. J.A. and J.H.S. performed the experiments. J.M. 
performed data analyses. J.A. and K.Y. wrote the manuscript. All authors have read and approved the final manuscript.

\section{CONFLICTS OF INTEREST}

No author has any conflicts of interest.

\section{FUNDING}

This work was supported by Zhejiang Provincial Natural Science Foundation of China (LQ14H120001); National Natural Science Foundation of China (81371658); Zhejiang Key Laboratory Fund of China (2011E10006); Project of National Clinical Key Discipline of Chinese Ministry of Health and Zhejiang Province Key Research and Development Program (2015C03042); National Natural Science Foundation of China (81371001, 81570822); Zhejiang Provincial Natural Science Foundation of China (LY14H120004).

\section{REFERENCES}

1. Kikuchi E, Menendez S, Ohori M, Cordon-Cardo C, Kasahara N, Bochner BH. Inhibition of orthotopic human bladder tumor growth by lentiviral gene transfer of endostatin. Clin Cancer Res. 2004; 10: 1835-1842.

2. O'Reilly MS, Boehm T, Shing Y, Fukai N, Vasios G, Lane WS, Flynn E, Birkhead JR, Olsen BR, Folkman J. Endostatin: an endogenous inhibitor of angiogenesis and tumor growth. Cell. 1997; 88: 277-285.

3. Bai YJ, Huang LZ, Zhou AY, Zhao M, Yu WZ, Li $X X$. Antiangiogenesis effects of endostatin in retinal neovascularization. J Ocul Pharmacol Ther. 2013; 29: 619-626.

4. Cockrell AS, Kafri T. Gene delivery by lentivirus vectors. Mol Biotechnol. 2007; 36: 184-204.

5. Shichinohe T, Bochner BH, Mizutani K, Nishida M, Hegerich-Gilliam S, Naldini L, Kasahara N. Development of lentiviral vectors for antiangiogenic gene delivery. Cancer Gene Ther. 2001; 8: 879-889.

6. Naldini L, Blömer U, Gallay P, Ory D, Mulligan R, Gage FH, Verma IM, Trono D. In vivo gene delivery and stable transduction of nondividing cells by a lentiviral vector. Science. 1996; 272: 263-267.

7. Folkman J. Antiangiogenic gene therapy. Proc Nat Acad Sci USA. 1998; 95: 9064-9066.

8. Kong HL, Crystal RG. Gene therapy strategies for tumor antiangiogenesis. J Nat Cancer Instit. 1998; 90: 273-286.

9. Chen QR, Zhang L, Gasper W, Mixson AJ. Targeting tumor angiogenesis with gene therapy. Mol Genet Metab. 2001; 74: 120-127.

10. Xu F, Ma Q, Sha H. Optimizing drug delivery for enhancing therapeutic efficacy of recombinant human endostatin in cancer treatment. Crit Rev Thera Drug Car Sys. 2007; 24: 445-492.

11. Matsumoto G, Hirohata R, Hayashi K, Sugimoto Y, Kotani E, Shimabukuro J, Hirano T, Nakajima Y, Kawamata S, Mori H. Control of angiogenesis by VEGF and endostatinencapsulated protein microcrystals and inhibition of tumor angiogenesis. Biomaterials. 2014; 35, 1326-1333.

12. Zambon L, Honma HN, Lourenço GJ, Saad IA, Mussi RK, Lima CS. A polymorphism in the angiogenesis inhibitor, endostatin, in lung cancer susceptibility. Lung Cancer. 2008; 59: 276-278.

13. Mori K, Duh E, Gehlbach P, Ando A, Takahashi K, Pearlman J, Mori K, Yang HS, Zack DJ, Ettyreddy D, Brough DE, Wei LL, Campochiaro PA. Pigment epithelium-derived factor inhibits retinal and choroidal neovascularization. J Cell Physiol. 2001; 188: 253-263.

14. Yu YJ, Mo B, Liu L, Yue YK, Yue CL, Liu W. Inhibition of choroidal neovascularization by lentivirus-mediated PEDF gene transfer in rats. Int J Ophthalmol. 2016; 9: 1112-1120.

15. Zhou XY, Liao Q, Pu YM, Tang YQ, Gong X, Li J, Xu Y, Wang ZG. Ultrasound-mediated microbubble delivery of pigment epithelium-derived factor gene into retina inhibits choroidal neovascularization. Chin Med J (Engl). 2009; 122: 2711-2717.

16. Caballero S, Sengupta N, Afzal A, Chang KH, Li Calzi S, Guberski DL, Kern TS, Grant MB. Ischemic vascular damage can be repaired by healthy, but not diabetic, endothelial progenitor cells. Diabetes. 2007; 56: 960-967.

17. Song MB, Yu XJ, Zhu GX, Chen JF, Zhao G, Huang L. Transfection of HGF gene enhances endothelial progenitor cell (EPC) function and improves EPC transplant efficiency for balloon-induced arterial injury in hypercholesterolemic rats. Vasc Pharmacol. 2009; 51: 205-213.

18. Assmus B, Schächinger V, Teupe C, Britten M, Lehmann R, Döbert N, Grünwald F, Aicher A, Urbich C, Martin H, Hoelzer D, Dimmeler S, Zeiher AM. Transplantation of progenitor cells and regeneration enhancement in acute myocardial infarction (TOPCARE-AMI). Circulation. 2002; 106: 3009-3017.

19. Tateishi-Yuyama E, Matsubara H, Murohara T, Ikeda U, Shintani S, Masaki H, Amano K, Kishimoto Y, Yoshimoto K, Akashi H, Shimada K, Iwasaka T, Imaizumi T. Therapeutic Angiogenesis using Cell Transplantation (TACT) Study Investigators. Therapeutic angiogenesis for patients with limb ischaemia by autologous transplantation of bone-marrow cells: a pilot study and a randomised controlled trial. Lancet. 2002; 360: 427-435.

20. Inaba S, Egashira K, Komori K. Peripheral-blood or bonemarrow mononuclear cells for therapeutic angiogenesis? Lancet. 2002; 360: 2083.

21. Marsboom G, Janssens S. Endothelial progenitor cells: new perspectives and applications in cardiovascular therapies. Exp Rev Cardiovasc Ther. 2008; 6: 687-701. 
22. Kerbel R, Folkman J. Clinical translation of angiogenesis inhibitors. Nat Rev Cancer. 2002; 2: 727-739.

23. Schaper W, Scholz D. Factors regulating arteriogenesis. Arterioscler Thromb Vasc Biol. 2003; 23: 1143-1151.

24. Asahara T, Murohara T, Sullivan A, Silver M, van der Zee R, Li T, Witzenbichler B, Schatteman G, Isner JM. Isolation of putative progenitor endothelial cells for angiogenesis. Science. 1997; 275: 964-967.

25. Szary J, Szala S. Intra-tumoral administration of naked plasmid DNA encoding mouse endostatin inhibits renal carcinoma growth. Int J Cancer. 2001; 91: 835-839.

26. Singer O, Verma IM. Applications of lentiviral vectors for shRNA delivery and transgenesis. Curr Gene Ther. 2008; 8: 483-488.

27. Naldini L. Medicine: a comeback for gene therapy. Science. 2009; 326: 805-806.

28. Dvorak HF, Brown LF, Detmar M, Dvorak AM. Vascular permeability factor/vascular endothelial growth factor, microvascular hyperpermeability, and angiogenesis. Am J Pathol. 1995; 146: 1029-1039.

29. Aiello LP, Wong JS. Role of vascular endothelial growth factor in diabetic vascular complications. Kidney Int Supp. 2000; 77: S113-S119.
30. Iwaguro H, Yamaguchi J, Kalka C, Murasawa S, Masuda H, Hayashi S, Silver M, Li T, Isner JM, Asahara T. Endothelial progenitor cell vascular endothelial growth factor gene transfer for vascular regeneration. Circulation. 2002; 105: 732-738.

31. Ma H, Calderon TM, Fallon JT, Berman JW. Hepatocyte growth factor is a survival factor for endothelial cells and is expressed in human atherosclerotic plaques. Atherosclerosis. 2002; 164: 79-87.

32. Huang $\mathrm{C}$, Zheng $\mathrm{X}$, Mei H, Zhou M. Rescuing Impaired Re-endothelialization of Drug-Eluting Stents Using the Hepatocyte Growth Factor. Ann Vasc Surg. 2016; 36: 273-282.

33. Kim YM, Hwang S, Kim YM, Pyun BJ, Kim TY, Lee ST, Gho YS, Kwon YG. Endostatin blocks vascular endothelial growth factor-mediated signaling via direct interaction with KDR/Flk-1. J Biol Chem. 2002; 277: 27872-27879.

34. Sun JH, Zhang YL, Nie CH, Qian SP, Yu XB, Xie HY, Zhou $\mathrm{L}$, Zheng SS. In vitro labeling of endothelial progenitor cells isolated from peripheral blood with superparamagneticiron oxide nanoparticles. Mol Med Rep. 2012; 6: 282-286. 